Terr. Atmos. Ocean. Sci., Vol. 18, No. 3, 493-514, August 2007

\title{
SUNYA Regional Climate Model Simulations of East Asia Summer Monsoon: Effects of Cloud Vertical Structure on the Surface Energy Balance
}

\author{
Wei Gong ${ }^{1,}{ }^{*}$ and Wei-Chyung Wang ${ }^{1}$
}

(Manuscript received 22 May 2006, in final form 9 February 2007)

\begin{abstract}
We used the State University of New York at Albany (SUNYA) regional climate model to study the effect of cloud vertical distribution in affecting the surface energy balance of the East Asia summer monsoon (EASM). Simulations were conducted for the summers of 1988 and 1989, during which large contrast in the intra-seasonal cloud radiative forcing (CRF) was observed at the top of the atmosphere.

The model results indicate that both the high and low clouds are persistent throughout the summer months in both years. Because of large cloud water, low clouds significantly reduce the solar radiation flux reaching the surface, which nevertheless still dominate the surface energy balance, accounting for more than $\mathbf{5 0 \%}$ of the surface heating. The low clouds also contribute significantly the downward longwave radiation to the surface with values strongly dependent on the cloud base temperature. The presence of low clouds effectively decreases the temperature and moisture gradients near surface, resulting in a substantial decrease in the sensible and latent heat fluxes from surface, which partially compensate the decrease of the net radiative cooling of the surface. For example, in the two days, May 8 and July 11 of 1988 , the total cloud cover of $80 \%$ is simulated, but the respective low cloud cover (water) was $63 \%\left(114 \mathrm{gm}^{-2}\right)$ and $22 \%\left(21 \mathrm{gm}^{-2}\right)$. As a result, the downward solar radiation is smaller by $161 \mathrm{Wm}^{-2}$ in May 8. On the other hand, the cloud temperature was $10^{\circ} \mathrm{C}$ lower, yielding $56 \mathrm{Wm}^{-2}$ smaller downward longwave radiation. The near surface temperature and
\end{abstract}

\footnotetext{
${ }^{1}$ Atmospheric Sciences Research Center, State University of New York, Albany, New York, USA

* Corresponding author address: Dr. Wei Gong, Atmospheric Sciences Research Center, State University of New York, Albany, New York, USA; E-mail: wgong@climate.cestm.albany.edu doi: 10.3319/TAO.2007.18.3.493(EA)
} 
gradient is more than $1^{\circ} \mathrm{C}$ smaller (and moisture gradient), leading to 21 and $81 \mathrm{Wm}^{-2}$ smaller sensible heat and latent heat fluxes.

It is also demonstrated that the model is capable to reproduce the intra-seasonal variation of shortwave $\mathrm{CRF}$, and catches the relationship between total cloud cover and SW CRF. The model results show the dominance of high cloud on the regional mean longwave CRF and low cloud on the intra-seasonal variation of shortwave CRF, indicating the importance of cloud vertical structure.

The strong negative feedbacks from the responses of latent and sensible heat flux tend to limit the effects of low clouds on the surface temperature simulations, as evidently the surface air temperatures bias of only $0.34^{\circ} \mathrm{C}$ in the EASM simulations while the variances of the surface radiative fluxes and heat fluxes are, respectively, in the ranges of 100 - 200 and $60-110 \mathrm{Wm}^{-2}$ when total cloud cover are all near $80 \%$. Therefore, it is also concluded that surface air temperature, precipitation, and total cloud cover, which are three frequently examined variables for climate models, are not sufficient for model evaluation, but instead the cloud vertical structure needs to be examined.

(Key words: Cloud radiative forcing, East Asia summer monsoon, Regional climate model)

\section{INTRODUCTION}

East Asia summer monsoon (EASM) is characterized by heavy and persistent precipitation closely associated with clouds, which are known to provide significant radiative effects through reflection of incoming solar radiation (the albedo "cooling" effect) and trapping of outgoing longwave radiation (the greenhouse "warming" effect). Consequently, clouds dominate the radiation budget at the top of the atmosphere (TOA) and on the surface as well as providing a key component of the vertical heating/cooling distribution. On the other hand, cloud formation and its life cycle depend strongly on the climate and environment where the clouds embedded in, thus as indicated in Wang et al. (2004a), the cloud-climate interaction can play a important role in EASM evolution.

There have been many observational and modeling studies that investigate the characteristics of clouds and their influences on the radiation budget, general circulation, and surface climate in the broader Asian summer monsoon region. Rajeevan and Srinivasan (2000) analyzed the Earth Radiation Budget Experiments (ERBE) data and found that the large negative net cloud radiative forcing $(\mathrm{CRF})$ at TOA is mainly caused by the presence of extensive, optically thick high clouds. Yu et al. (2004) demonstrated that there are strong coupling among the optically thick deep stratus clouds, moisture, and vertical stratification over the lee side of the Tibetan Plateau. Joseph and Sijikumar (2004) suggested that the cross-equatorial low level jet may result in convergence and upward motion that favors the deep convective activity, and 
thus generates thick clouds. Iwasaki and Kitagawa (1998) conducted a GCM sensitivity study of the effect of aerosol-cloud radiation interaction, and demonstrated that the interaction reduces the absorption of solar radiation over land surface, suppressing the monsoonal flow in Southeast Asia, and significantly delaying the northward migration of the fronts around East Asia.

Recently, Wang et al. (2004a) used both observational data [ERBE and International Satellite Cloud Climatology Project (ISCCP-C2)] and general circulation model (GCM) simulations to study the seasonal and spatial characteristics of TOA CRF over East Asia $\left(23-43^{\circ} \mathrm{N}\right.$, $105-123^{\circ} \mathrm{E}$ ). They found that the net CRF provide a significant cooling effect (dominated by the SW CRF) to the atmosphere-surface climate system, which is in sharp contrast to the Northern Hemispheric zonal means of the same latitude bands and seasons, thus implying a unique role for cloud-radiation interaction in East China. The GCM simulations show similar observed characteristics, although biases exist, attributable to biases in clouds. In addition, there is a relationship between SW CRF and total cloud cover, and between LW CRF and high cloud cover, implying the importance of vertical cloud distribution to the EASM. However, due to uncertainties in the observed low and middle clouds, as illustrated in Wang et al. (2004a), the effects of cloud at different levels on the surface climate (both temperature and energy balance involving sensible and latent heat fluxes), remain to be investigated.

In recent years, regional climate models (RCMs) have been developed for studying EASM (see Wang et al. 2004b for a review). The RCMs simulate consistently the climate parameters within the Earth-atmosphere climate system, thus allowing a detailed analysis of the effects of clouds on the TOA CRF and the surface energy balance, including the direct effects of clouds on shortwave and longwave radiative fluxes, and the subsequent responses of sensible and latent heat fluxes. In the present study, we use the State University of New York at Albany (SUNYA) RCM to study these aspects. Below, in Section 2, we provide a description of the SUNYA RCM and the simulated surface temperature, precipitation and clouds in the summers of 1988 and 1989. The effects of cloud vertical distribution on TOA cloud radiative forcing and surface energy balance are given in Sections 3 and 4, respectively. The conclusions and discussion are summarized in Section 5.

\section{EASM SIMULATIONS}

\subsection{Model}

The SUNYA RCM, evolved from National Center for Atmospheric Research (NCAR) Mesoscale Model version 5, has been used to study the 1991 severe flood event over the Yangtze-Huai River valley (YHRV) focusing on the ability to simulate the spatial and temporal precipitation patterns (Gong and Wang 2000; Wang et al. 2000) and the sensitivity of rainfall to cloud parameterization (Cheng and Wang 2005). The present study is based on the latest version, although we switched to the Kain-Fritsch convective scheme to provide sufficient removal of the convective available potential energy (Kuo et al. 1996). The scheme, suitable for application to grid size of several tens of kilometers, is found to provide the best simulation among several convective schemes (Ferretti et al. 2000). The cloud cover is diagnosed based on relative humidity, atmosphere layer stability, and convective precipitation 
(Liang and Wang 1995), while the cloud water uses a hybrid scheme which, as indicated in Cheng and Wang (2005), simulates the least biases in shortwave (SW) cloud radiative forcing (CRF) and subsequently yields a surface temperature in better agreement with observation. For the radiation calculation, CCM3 radiation scheme (Kiehl et al. 1996), in which cloud random overlapping is assumed, is used.

The simulation domain and relevant resolutions are the same as in previous studies, i.e., a horizontal resolution of $60 \mathrm{~km}$ with a mesh of $85 \times 65$ (centered at $120^{\circ} \mathrm{E}$ and $30^{\circ} \mathrm{N}$ ), 23 vertical layers, which is the same as standard MM5, and a linear-relaxation buffer zone of 18-grid points. Analyses of the simulation results focused on two regions, the YHRV $\left(30-34^{\circ} \mathrm{N}\right.$, $\left.105-122^{\circ} \mathrm{E}\right)$ and North China $\left(34-39^{\circ} \mathrm{N}, 105-122^{\circ} \mathrm{E}\right)$, to reflect the regional contrast. We conduct 1 May - 31 August simulations of EASM for 1988 and 1989, the two years of the 1985 - 89 period in which the monthly mean shortwave (SW) cloud radiative forcing (CRF) and longwave (LW) CRF at TOA from ERBE and cloud cover information from ISCCP-C2 were available. We use European Center for Medium-Range Weather Forecasts (ECMWF) objective analysis as the atmospheric driving fields and National Meteorological Center (NMC) objective analysis for the sea surface temperature (SST), both archived at NCAR (http://dss.ucar.edu/datasets/ds111.2 and http://dss.ucar.edu/datasets/ds082.0), because the former analysis does not provide SST while the latter has missing atmospheric data during the simulation periods. Based on our experiments using different starting date (not shown), the model spin-up time is about 3 days, and therefore the monthly mean results are not significantly affected by the model spin-up. As discussed in Section 3, the observed SW CRF over (YHRV) were almost identical in May between the two years, but significantly different in June and July, thus providing a good contrast to study the seasonal and interannual variation and its association with clouds. In addition, the CRF values for 1989 are also very close to the 1985 - 89 five-years mean values. The low $(1000$ - $680 \mathrm{hPa})$, middle $(680-440 \mathrm{hPa})$ and high $(440-50 \mathrm{hPa})$ clouds are defined as the same as those used in ISCCP. Note that this definition of cloud is primarily used to analyze the effect of cloud vertical structure.

\subsection{Surface Temperature, Precipitation, and Cloud Covers}

Figure 1 compares the model simulated daily maximum and minimum surface air temperatures with observations over the two regions for both years. In general, the model reproduces the observed daily temperature variations as well as the regional contrast between North China and YHRV. The correlation between simulation and observation are also high. For example, maximum temperatures have correlation coefficients of 0.89 and 0.95 , respectively, for the two years over YHRV. However, differences exist with maximum values up to $4^{\circ} \mathrm{C}$ in several periods, for 1988 during first half of July in North China and mid-June in YHRV, and for 1989 during early May in North China and early July in YHRV.

For both years, there exists a seasonal cycle for maximum temperature with peak occurred in mid-July for YHRV, while the minimum temperature highly correlated with the maximum temperature, especially over YHRV. Meanwhile, the short-term variations in YHRV are generally more active in May - June than that in July - August, reflecting the effects of cloud bands associated with the north-south movement of Mei-Yu front (see Wang et al. 2000). 

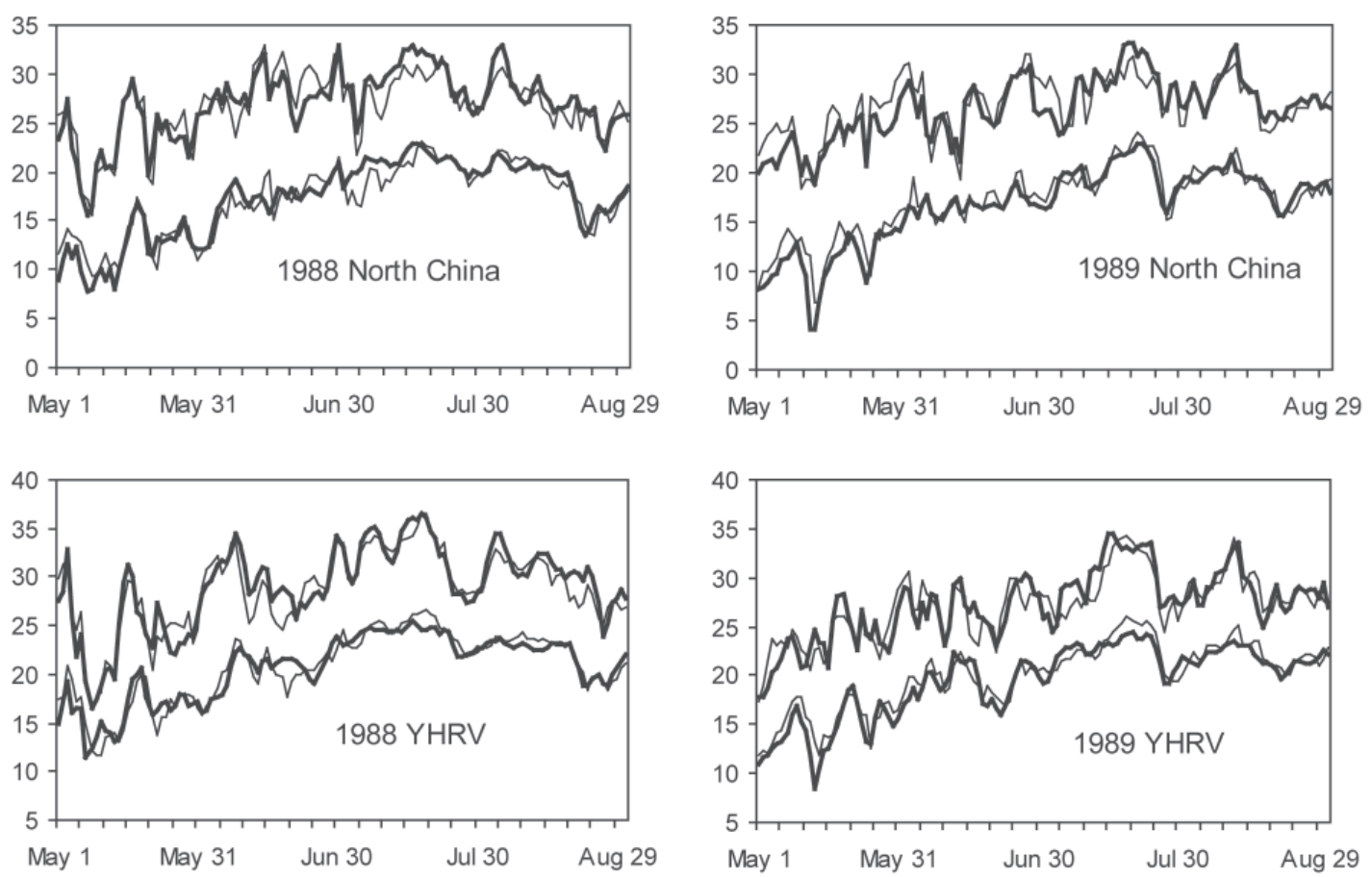

Fig. 1. Comparison of May - August daily maximum and minimum surface air temperatures $\left({ }^{\circ} \mathrm{C}\right)$ over YHRV between observations (thin lines) and model simulations (thick lines). The observational data is from NCAR DS512 (available at http://dss.ucar.edu/datasets/ds512.0) data set, and there are over 100 stations in the two regions.

The model also simulates these observed characteristics quite well. For example, the model catches the sudden cooling events, with amplitude of $10^{\circ} \mathrm{C}$ in YHRV on integration day 3 - 7 in 1988 and integration day $85-89$ in 1989. The good agreements can also be seen in Table 1 for YHRV, in which the simulated four-months mean values for all three temperatures in both years are within a few tenth of a degree of the respective observations.

Comparison of the precipitation, which is sensitive to clouds, is shown in Fig. 2. For observations, in general, there is a tendency for more light rainfall with distinctive breaks in June - July, while persistent heavier rainfall occurred in July and August, but variations between these two years can also be seen, for example, in early July and late August. As listed in Table 1, the observed four-month mean was larger in $1989\left(5.37 \mathrm{~mm} \mathrm{day}^{-1}\right)$ than in $1988\left(4.56 \mathrm{~mm} \mathrm{day}^{-1}\right)$. The model simulates reasonably well the daily precipitation variability in both years, in particular the changes in characteristics from May - June to July - August. Over the YHRV, the four-month mean values are 5.17 and $5.67 \mathrm{~mm} \mathrm{day}^{-1}$, for 1988 and 1989 are larger than the 
respective observations. The major differences can be clearly seen in the rainfall characteristics in July - August, during which the model does not, in particular in 1988, simulate the clear breaks as seen in the observations.

To demonstrate the circulation simulated by SUNYA RCM, in Fig. 3, we show $850 \mathrm{hPa}$ wind vector and water vapor mixing ratio, against the ECMWF analysis, in May - August of 1989. In objective analysis the wind is characterized by the southwest wind from India and southeast wind from western Pacific. These two winds merge between $110-130^{\circ} \mathrm{E}$, and turn south. The water vapor that affects East Asia is clearly associated with the southwest wind, and has a maximum above $16 \mathrm{~g} \mathrm{~kg}^{-1}$ at $100^{\circ} \mathrm{E}$ and $20^{\circ} \mathrm{N}$. The model reproduces the summer monsoon circulation quite well, although it under-simulates the water vapor mixing ratio in the South China and YHRV. Note that the water vapor bias is consistent with the over-simulation of precipitation as shown above.

Because of available ISCCP data, we compare in Table 1 the total and high cloud covers between the model and observation. Note that for accurate model-satellite comparison, cloud simulators, such as those suggested by Yu et al. (1996) and Klein and Jakob (1999), are required. Because it will take large effort to do the cloud transform and the paper do not focus on the cloud cover verification, but on the effect of cloud vertical structure, we directly compare

Table 1. Observed and model simulated 1988 and 1989 four months mean statistics over YHRV: shortwave (SW) cloud radiative forcing $\left(\mathrm{CRF} ; \mathrm{Wm}^{-2}\right.$ ) and longwave ( $\mathrm{LW}) \mathrm{CRF}\left(\mathrm{Wm}^{-2}\right)$ at the top of the atmosphere; surface mean $\left(\mathrm{T}_{\mathrm{m}}\right)$, maximum $\left(\mathrm{T}_{\max }\right)$, and minimum $\left(\mathrm{T}_{\min }\right)$ air temperature $\left({ }^{\circ} \mathrm{C}\right)$; precipitation $\left(\mathrm{P}, \mathrm{mm}\right.$ day $\left.^{-1}\right)$; total cloud cover $(\mathrm{C})$ and high cloud cover $\left(\mathrm{C}_{\mathrm{h}}\right)$. Observed temperatures and precipitation are from station observation, and cloud covers are from ISCCP C2.

\begin{tabular}{c|cc|cc}
\hline \multirow{2}{*}{ Parameter } & \multicolumn{2}{|c|}{$\mathbf{1 9 8 8}$} & \multicolumn{2}{c}{$\mathbf{1 9 8 9}$} \\
\cline { 2 - 5 } & Obs. & Model & Obs. & Model \\
\hline SW CRF & -91.70 & -85.33 & -106.96 & -113.56 \\
LW CRF & 46.76 & 24.72 & 51.70 & 29.49 \\
$\mathrm{~T}_{\mathrm{m}}$ & 24.79 & 24.90 & 23.53 & 23.35 \\
$\mathrm{~T}_{\max }$ & 28.80 & 29.14 & 27.11 & 27.26 \\
$\mathrm{~T}_{\min }$ & 20.79 & 20.66 & 19.96 & 19.44 \\
$\mathrm{P}$ & 4.56 & 5.17 & 5.37 & 5.67 \\
$\mathrm{C}$ & 67.93 & 58.81 & 72.43 & 69.35 \\
$\mathrm{C}_{\mathrm{h}}$ & 33.19 & 41.83 & 37.96 & 56.17 \\
\hline
\end{tabular}


modeled cloud against satellite observation. Although the model total cloud values are in reasonably good agreement with observation, for example, for YHRV, the four-months mean values of model simulations and observations are, respectively, 59\% and 68\% in 1988, and $69 \%$ and $72 \%$ in 1989. But the model simulates much larger high cloud cover, in particular in 1989. The simulation results also indicate that, for both years, the clouds are dominated by low and high clouds, with much smaller middle clouds. The four-months mean low cloud covers are $26.2 \%$ for 1988 and $31.6 \%$ for 1989 .

\section{TOA CLOUD RADIATIVE FORCING}

The CRF is defined as the difference in the outgoing radiative flux at the top of the atmosphere (TOA) between clear and cloudy-sky condition. This macroscopic parameter has taken into account contributions from cloud cover, cloud optical depth, and cloud emissivity, providing direct and useful information about the cloud-climate interaction (see Cheng and Wang 2005 for a more detailed definition).
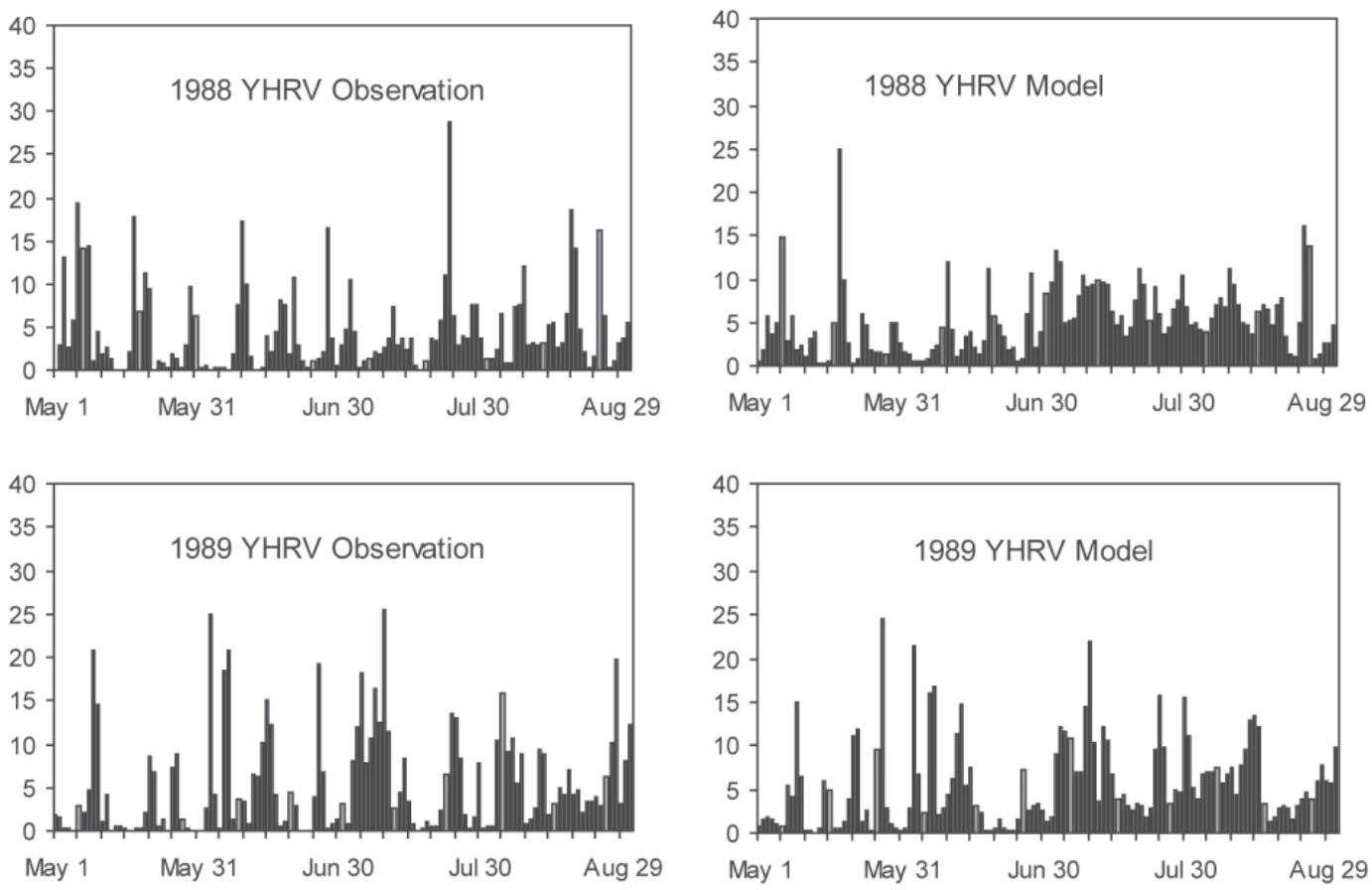

Fig. 2. May - August daily precipitation (mm) over YHRV. The observation data set is obtained from the WMO station data archived at NCAR (http:/ (dss.ucar.edu/datasets/ds512.0). 

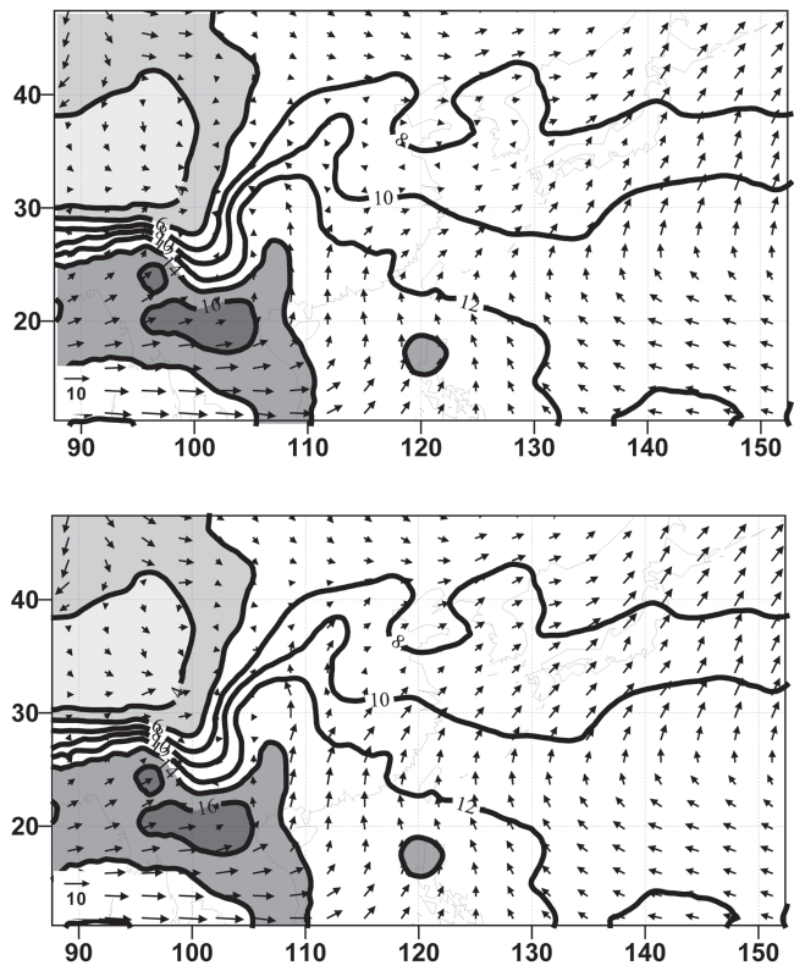

Fig. 3. 1989 ECMWF (upper panel) and SUNYA RCM (lower panel) May August $850 \mathrm{hPa}$ wind vector $\left(\mathrm{m} \mathrm{s}^{-1}\right)$ and water vapor mixing ratio $\left(\mathrm{g} \mathrm{kg}^{-1}\right)$. Unit vector wind is $10 \mathrm{~m} \mathrm{~s}^{-1}$. Contour interval is $2\left(\mathrm{~g} \mathrm{~kg}^{-1}\right)$. Contours less than $6 \mathrm{~g} \mathrm{~kg}^{-1}$ and greater than $14 \mathrm{~g} \mathrm{~kg}^{-1}$ are shaded.

Table 2 shows the comparison of net CRF between model simulations and ERBE for North China and YHRV. In YHRV, the observed net CRF decreases from May to August for both years, reflecting the northward movement of clouds, although the May - June transition between the two years was quite different-a sharp drop of $24 \mathrm{Wm}^{-2}$ occurred in 1988 versus almost unchanged values in 1989, suggesting different cloud characteristics after the onset of the monsoon season. For North China, both years showed a peak net CRF of around $50 \mathrm{Wm}^{-2}$ in July, indicating a different seasonal trend from YHRV. The contrast in the May - June transition between 1888 and 1989, however, is similar to YHRV but with smaller magnitude in 1988. When compared with ERBE data, the model calculates larger net CRF values, in particular in YHRV with maximum difference reaching $37 \mathrm{Wm}^{-2}$ in May 1988 and $20 \mathrm{Wm}^{-2}$ in May - June 1989. As noted in Wang et al. (2004a), the net CRF consists of two components, a dominant cooling by SW CRF due to low clouds and a warming by LW CRF attributed to high clouds. 
Table 2. Comparison of observed and the model simulated net cloud radiative forcing $\left(\mathrm{Wm}^{-2}\right)$ at the top of the atmosphere for North China (NC) and Yangtze-Huai River Valley (YHRV). Note that positive value indicates a cooling of the Earth-atmosphere climate system. The forcing consists of a dominant cooling due to SW and a warming due to $\mathrm{LW}$, both are shown in Fig. 3. The observations are from the Earth Radiation Budget Experiments (ERBE).

\begin{tabular}{lr|cc|cc}
\hline & & $\begin{array}{c}\text { ERBE } \\
\text { (NC) }\end{array}$ & $\begin{array}{c}\text { Model minus ERBE } \\
\text { (NC) }\end{array}$ & $\begin{array}{c}\text { ERBE } \\
\text { (YHRV) }\end{array}$ & $\begin{array}{c}\text { Model minus ERBE } \\
\text { (YHRV) }\end{array}$ \\
\hline $\mathbf{1 9 8 8}$ & & & & \\
& & & & 67.54 & 36.92 \\
& May & 34.71 & 12.03 & 43.18 & 12.47 \\
& June & 23.80 & -1.58 & 40.54 & 3.33 \\
& July & 49.80 & -5.97 & 28.51 & 8.70 \\
\hline \multirow{1989}{198}{} & August & 38.27 & & & \\
& & & 5.06 & 63.83 & 20.97 \\
& May & 27.11 & 14.31 & 60.36 & 19.91 \\
& June & 24.75 & -8.27 & 55.19 & 5.39 \\
& July & 51.35 & -7.40 & 41.67 & 15.32 \\
\hline
\end{tabular}

Figure 4 shows the monthly mean observed and model simulated SW CRF (cooling) and LW CRF (warming) at TOA over YHRV and North China. In the observation the SW CRF shows large seasonal variation in both regions, although the contrast between 1988 and 1989 is small for North China, but quite substantial for YHRV. For example, the cooling over YHRV was decreased from $117 \mathrm{Wm}^{-2}$ in May to 75 and $83 \mathrm{Wm}^{-2}$ in August in 1988 and 1989, respectively. Over North China, a different seasonal trend was observed with maximum cooling occurred in July for both years. The different seasonal cycles of SW CRF between the two regions reflect the activity and evolution of EASM, during which precipitation and cloud band are active in early summer over YHRV and shifts to north China in mid-summer (see Wang et al. 2000). On the other hand, LW CRF shows a smaller warming with a weak seasonal cycle as well as its regional contrast.

In addition to the seasonal and latitudinal variations, there exists also large interannual variability of SW CRF over YHRV, also reflected in the CRF shown in Table 2. In 1988, SW CRF decreased from May to July and remained constant in August, while in 1989 a relatively constant value existed during May - June - July, but decreased significantly in August. Over North China, the contrast in seasonal cycle between 1988 and 1989 was small. Note however 

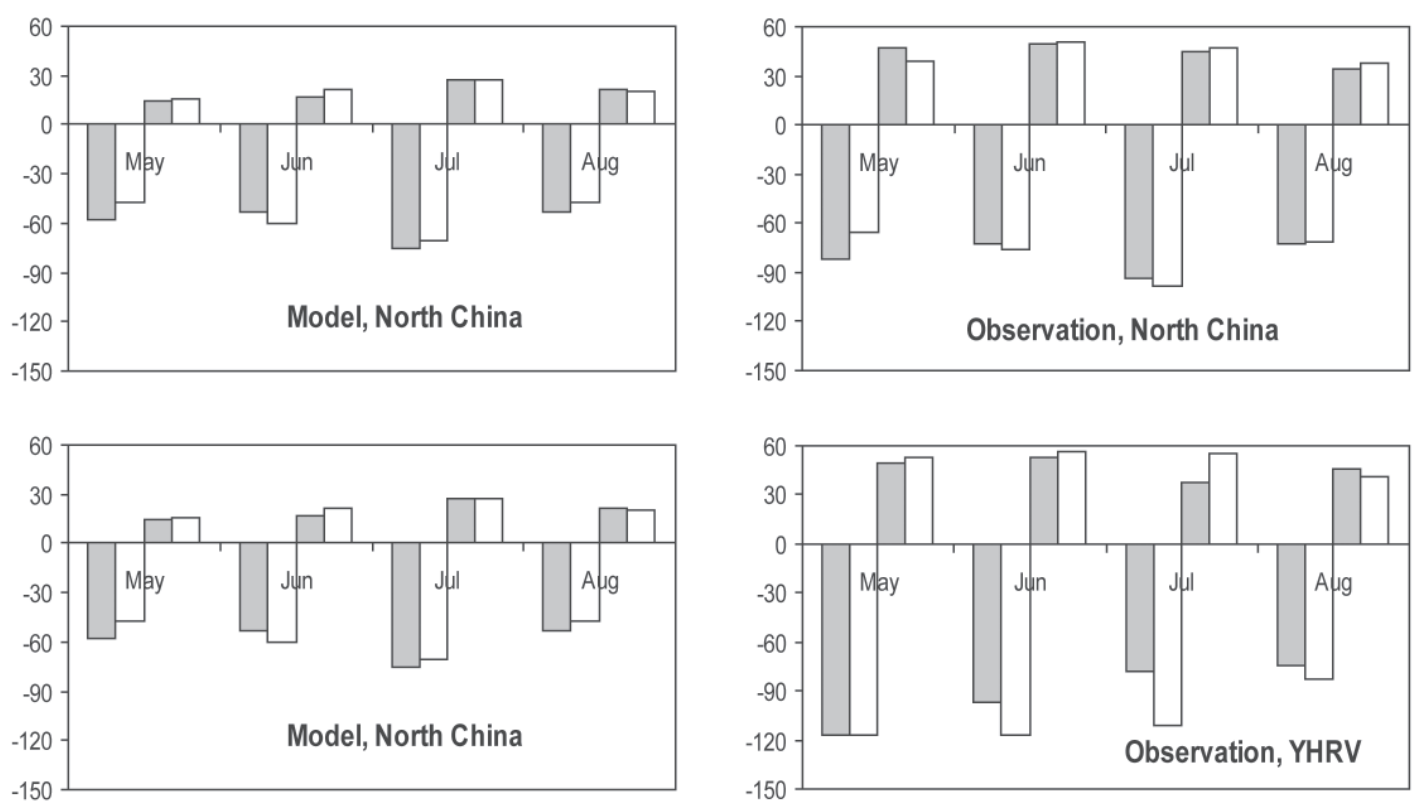

Fig. 4. The May - August monthly mean shortwave (negative) and longwave (positive) cloud radiative forcing $\left(\mathrm{Wm}^{-2}\right)$ in 1988 (solid bars) and 1989 (open bars).

that these characteristics were based on the monthly mean values, while the short term variation is fairly large as revealed from the model simulations.

For SW CRF, the SUNYA RCM reproduces several observed features. For example, the model catches the seasonal decrease from May - August and different phase (peak) between YHRV (May) and north China (July) for both years, and year-to-year variability (except in May). The dominance of SW CRF in net CRF over the two regions is also well represented in the simulation. However, the notable model biases exist, particular in North China. On the other hand, the model under-simulate LW CRF by almost a factor of two over the YHRV, as listed in Table 2. The seasonal variation in LW CRF is also not well simulated for both YHRV and North China. For both regions, the simulated LW CRF have their peaks in July, which are earlier than that of observation occurred in August. More detailed discussion on the possible causes for the biases will be given later.

As in Wang et al. (2004a), we also examine, as illustrated in Fig. 5, the relationship between the daily total cloud cover and SW CRF, and between high cloud cover and LW CRF. In general, the model reproduces well, particularly in 1988, the observed relationships (in the slopes and variances) for both the total and high cloud covers. The smaller slope in the model simulations of high clouds means the SUNYA RCM smaller cloud ice water content. Although we did not have the observational data to show the model bias in cloud ice, we have 
found that the cloud ice in SUNYA RCM is much less than that of IPRC RCM (Wang et al. 2003) in a model inter-comparison study for the 1989 simulation. Besides, Wang et al. (2004a) also indicated vertical distributions of temperature and moisture has a little effect on the LW CRF. On the monthly basis, the low cloud cover is found to be responsible for the SW CRF trend. For example, in 1988 low cloud cover decreases rapidly from 44.16\% in May to 22.16\% in June and remains under 20\% in July and August. In contrast, in 1989 the low cloud cover is above $30 \%$ in May and June, and decreases to about 25\% in July and August. This trend qualitatively corresponds to the SW CRF variation shown in Fig. 4.
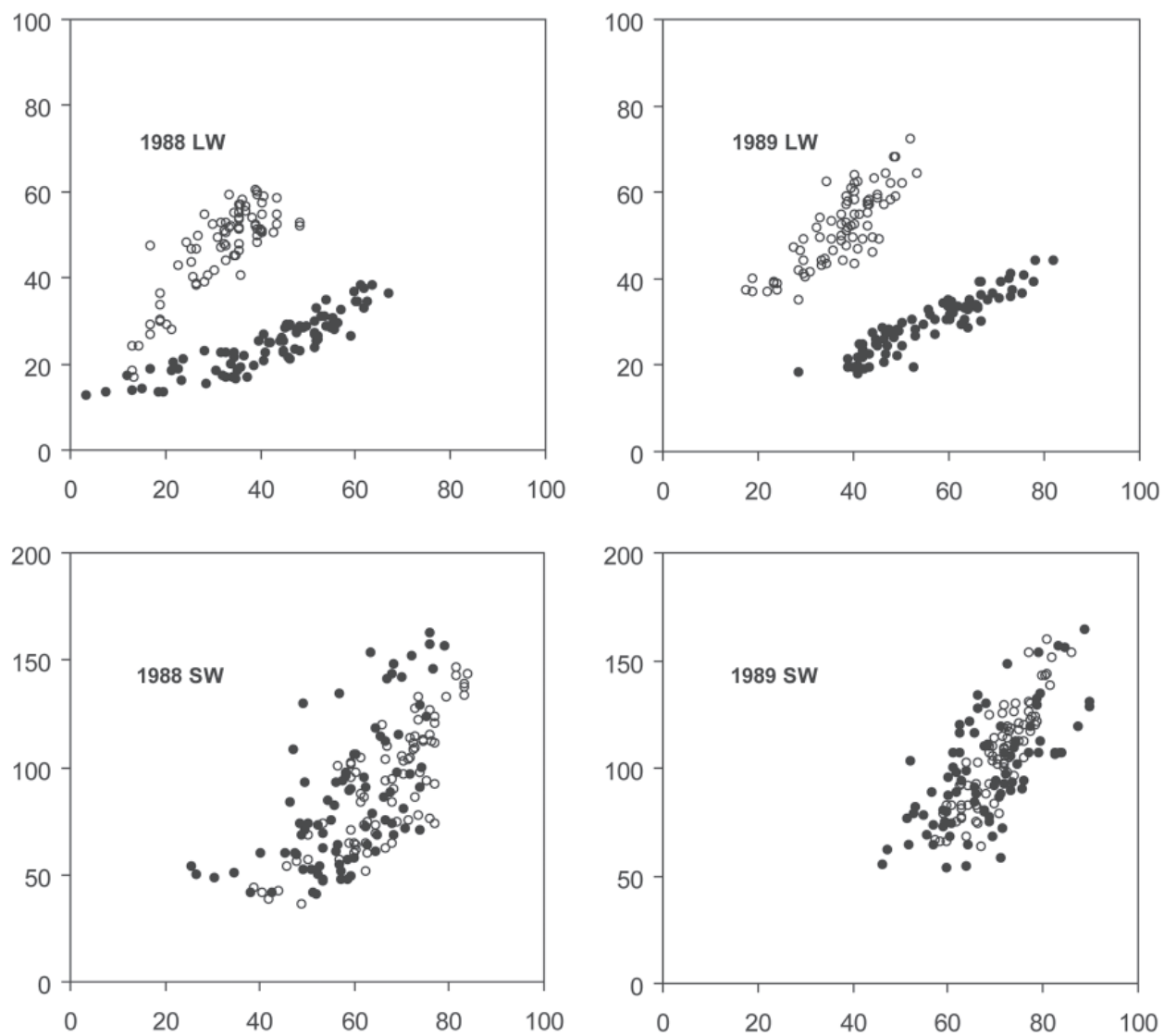

Fig. 5. Observed (०) and model simulated (•) correlation between LW CRF $\left(\mathrm{Wm}^{-2}\right)$ and high cloud cover (\%, upper panels; $\mathrm{x}$-axis) and between $\mathrm{SW}$ CRF $\left(\mathrm{Wm}^{-2}\right)$ and total cloud cover (\%; $\mathrm{x}$-axis) over YHRV. The values for the simulation are obtained by calculating the averages of model grid points within each observed box $\left(2.5^{\circ} \times 2.5^{\circ}\right)$, so that the resolution for observation and model is the same. 


\section{SURFACE ENERGY BALANCE}

\subsection{SW Radiation}

To illustrate the effect of vertical cloud structure on downward SW radiation reaching the surface, Fig. 6 shows the daily mean downward solar radiation versus the total cloud cover for YHRV in 1988 and 1989. Note that, in the figure, we further mark the cases with different percentage (to total cloud cover) of low clouds so that the effect of clouds at different levels can be identified when examining the relation between the SW radiation and total cloud cover. It is quite clear that the downward SW radiation decreases as the total cloud cover increases,
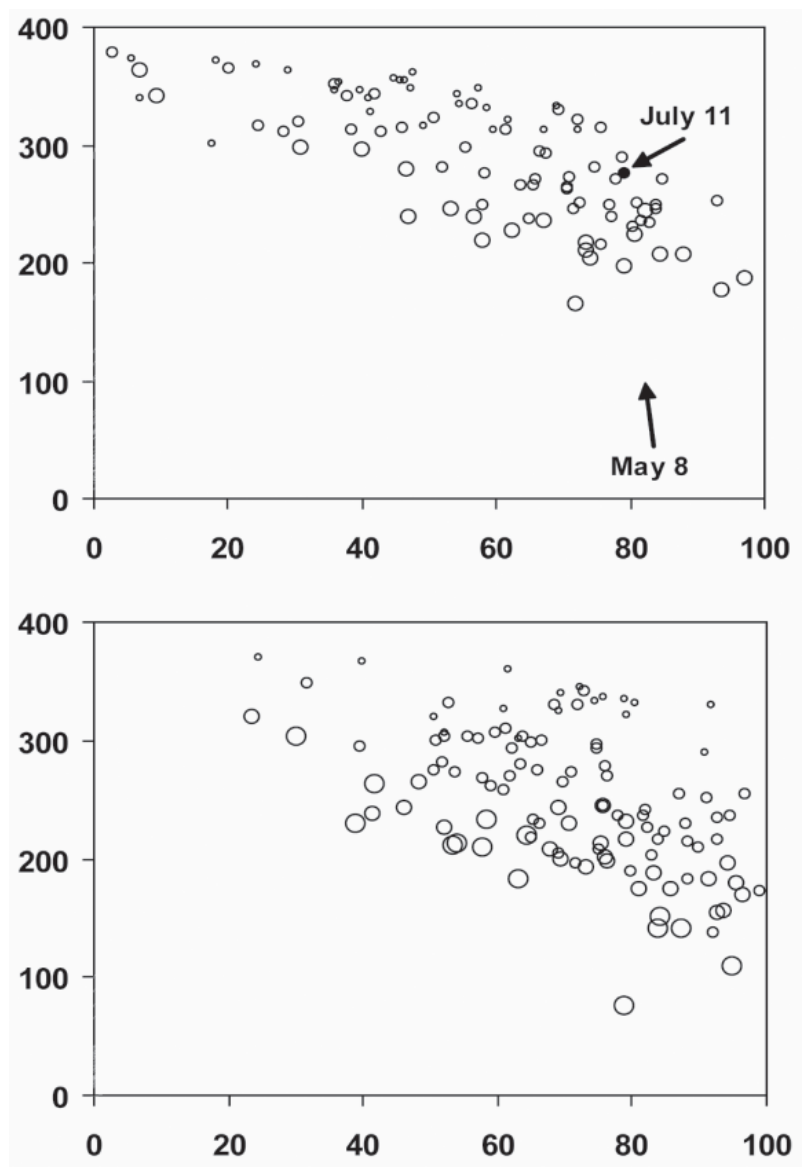

Fig. 6. Diagram of daily mean surface downward solar radiative flux and total cloud cover in May - August of 1988 (upper) and 1989 (lower panel). Ratio of low cloud cover and total cloud cover is depicted by five circles sizes at interval of 0.2. The arrows are for dates for Table 3 . 
especially when the total cloud cover is dominated by the presence of low clouds. The latter is particularly striking, when we single out two days, May 8 and July 11 in 1988 as marked in Fig. 6. As shown in Table 3, the total cloud cover for May 8 and July 11 is close, $81.0 \%$ and $79.2 \%$, respectively, but the vertical cloud distribution is very different, with May 8 dominated by low clouds $(63.4 \%)$ and July 11 by high clouds $(74.8 \%)$. Because of inherently more cloud water in low cloud and small in high clouds, for example as shown in Fig. 7, the SW radiation reaching surface shows significant difference, $104.9 \mathrm{Wm}^{-2}$ for May 8 and $276.3 \mathrm{Wm}^{-2}$ for July 11 . Thus this case highlights the importance of the vertical cloud distribution in determining the SW radiation reaching the surface. The much larger influence of low cloud on the SW radiation than that of high cloud is associated with the thicker cloud water content of low cloud. We have found that the SUNYA RCM simulates large difference in the cloud water between low and high clouds. For example, difference of high cloud water path is only $0.2 \mathrm{gm}^{-2}$, compared to $18.1 \mathrm{gm}^{-2}$ of low cloud on May 8. Similarly, the cloud water path on the monthly basis the low cloud water path $\left(29.2 \sim 92.7 \mathrm{gm}^{-2}\right)$ is also much larger than that of high cloud $(1.08 \sim$ $1.71 \mathrm{gm}^{-2}$ ). Thus, the much thicker low cloud has larger influence on the SW radiation than that of high cloud.

Table 3. The model simulated cloud properties and downward shortwave (SW, $\left.\mathrm{Wm}^{-2}\right)$ and longwave $\left(\mathrm{LW}, \mathrm{Wm}^{-2}\right)$ radiation reaching the surface in YHRV on May 8 and July 11, 1988, dates are also marked on Figs. 5 and 7. Parameters are: cloud cover (\%; total, $\mathrm{C}$; low, $\mathrm{C}_{\mathrm{l}}$; middle, $\mathrm{C}_{\mathrm{m}}$; and high, $\mathrm{C}_{\mathrm{h}}$ ), cloud water path (column, $\mathrm{Q}_{\mathrm{c}}$; and low, $\mathrm{Q}_{\mathrm{I}}$ ), and the cloud-base temperature $(\mathrm{T})$ of low clouds.

\begin{tabular}{ccc}
\hline & May 9 & July 11 \\
\hline $\mathrm{C}$ & 81.01 & 79.20 \\
$\mathrm{C}_{1}$ & 63.44 & 22.93 \\
$\mathrm{C}_{\mathrm{m}}$ & 53.06 & 11.12 \\
$\mathrm{C}_{\mathrm{h}}$ & 24.50 & 74.78 \\
$\mathrm{Q}_{\mathrm{c}}$ & 157.45 & 36.01 \\
$\mathrm{Q}_{1}$ & 114.48 & 21.78 \\
$\mathrm{~T}$ & 283.00 & 292.74 \\
$\mathrm{SW}$ & 104.88 & 276.31 \\
$\mathrm{LW}$ & 360.33 & 416.57 \\
\hline
\end{tabular}




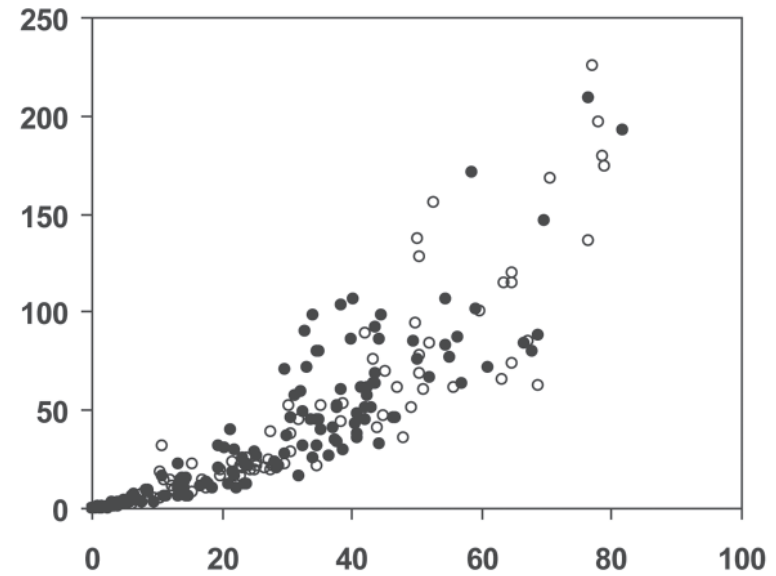

Fig. 7. Diagram of daily mean low cloud cover $(\%)$ and low cloud water mixing ratio $\left(\mathrm{g} \mathrm{kg}^{-1}\right)$ in May - August of $1988(\circ)$ and $1989(\bullet)$.

\subsection{LW Radiation}

Figure 8 shows the relation between the downward LW radiation reaching the surface versus the total cloud cover with the low cloud cover information indicated (percent of the total cloud cover). However, the situation is not as clear as in the case of SW radiation mainly because the cloud base temperature also plays an important role in determining the LW radiation reaching the surface. Again, as summarized in Table 3, the cloud temperature is only $283^{\circ} \mathrm{C}$ on May 8 , and is about $10^{\circ} \mathrm{C}$ colder than that of July 11 . Note that the reason of cloud temperature difference between these two days is beyond our research scope, although we think that it is probably due to the seasonal atmospheric warming from spring to summer. As a result, despite the larger low cloud cover occurs on the former day, the downward LW radiation is only $360.3 \mathrm{Wm}^{-2}$, which is about $56 \mathrm{Wm}^{-2}$ smaller than July 11 when low cloud cover is much less. This illustrates the complexity of the LW radiation reaching the surface which depends on a variety of factors, in particular the cloud base temperature.

\subsection{Sensible and Latent Heat Fluxes}

The ground is warmed by the net (downward minus the reflected) SW and downward LW radiation, but cooled by the emission of LW radiation, and releases of sensible and latent heat fluxes to the atmosphere; these heat fluxes depend respectively on the difference of temperature and moisture between the ground and near surface atmospheric layer. Consequently, low clouds will not only affect directly the SW and LW radiation reaching the surface as discussed above, but also indirectly the sensible and latent heat fluxes through modulating these temperature and moisture differences. 

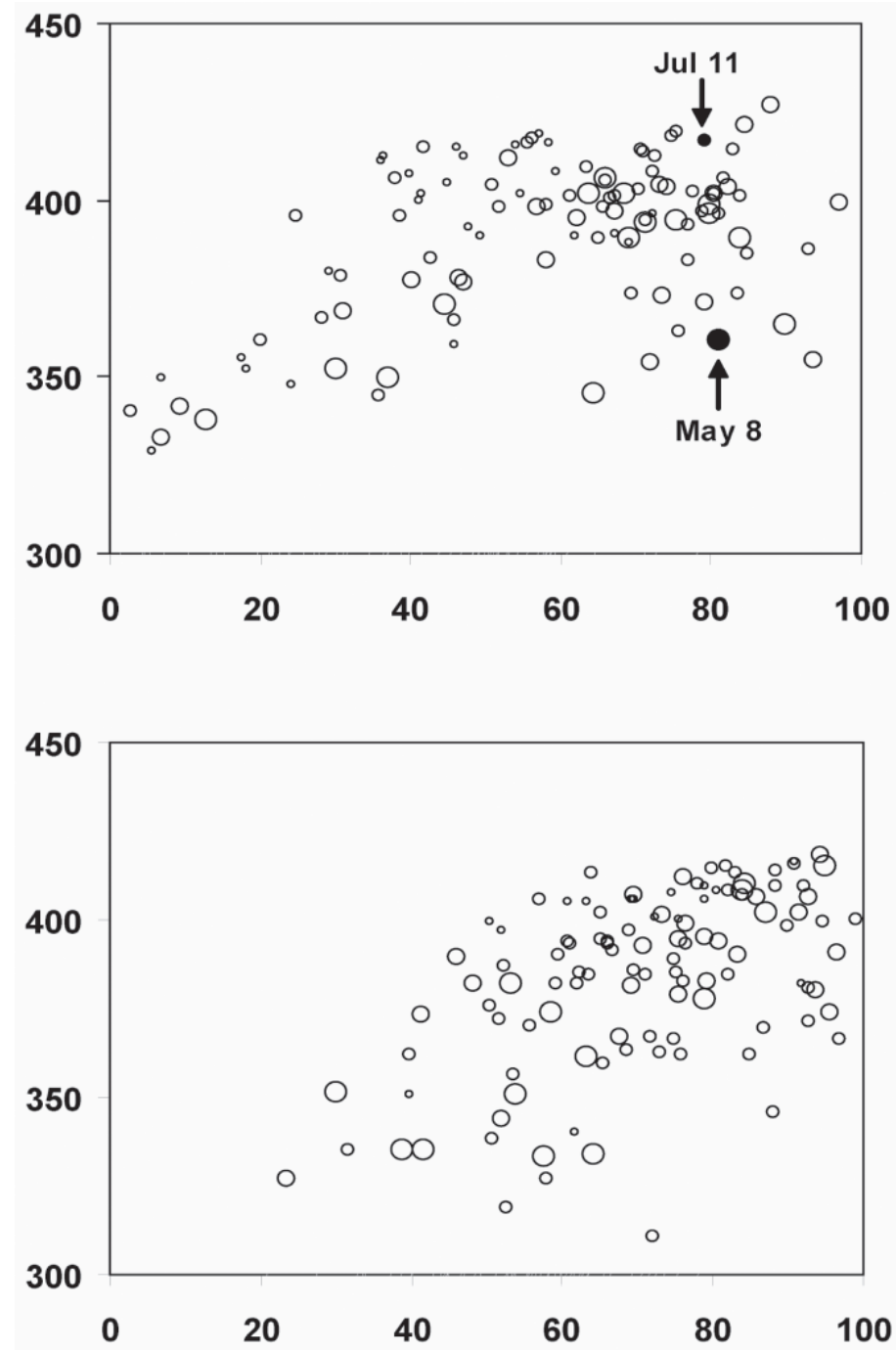

Fig. 8. Same as in Fig. 6, except for downward longwave radiative flux $\left(\mathrm{Wm}^{-2}\right)$.

To gain insights into this aspect, Figs. 9 and 10 illustrate respectively the latent and sensible heat fluxes versus the net SW plus downward LW radiation. Again, in these figures, both the information of low cloud cover (\% of total cloud cover) and the total cloud cover are identified. The results indicate that, for a given total cloud cover, more low cloud cover generally results in less latent and sensible heat fluxes. For example, the smaller net radiation flux and sensible and latent heat fluxes generally occur on those days with $80-100 \%$ total cloud cover and $75-100 \%$ low cloud cover ratio (large-dark circle), than days with $80-100 \%$ total 
cloud cover and 0 - 25\% low cloud cover ratio (large-open circle). In other words, more/less low clouds decrease/increase the radiative warming of the ground, but in the same time, the latent and sensible heat fluxes also decrease/increase, thus playing a negative feedback to the ground temperature.
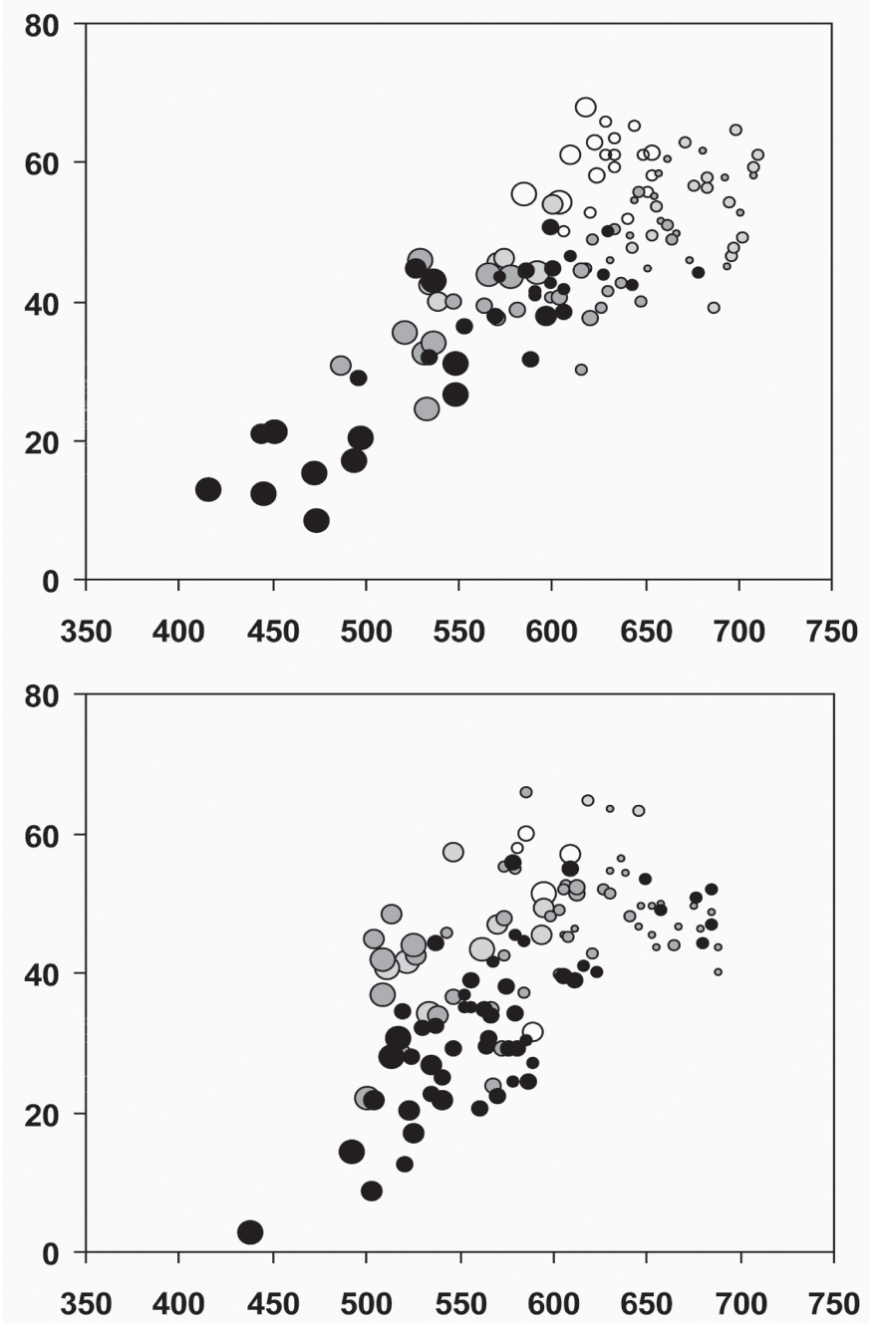

Fig. 9. Diagram of daily mean sensible heat flux $\left(\mathrm{Wm}^{-2}\right)$ against surface net solar and downward longwave radiative flux $\left(\mathrm{Wm}^{-2}\right)$ in May - August of 1988 (upper) and 1989 (lower panel). Total cloud cover is indicated by four shading intervals from no shading to dark: 0 - 20\%, 20 - 50\%, $50-75 \%$, and $75 \%-100 \%$. Ratio of low cloud cover and total cloud cover is depicted by five circles sizes at interval of 0.2 . 

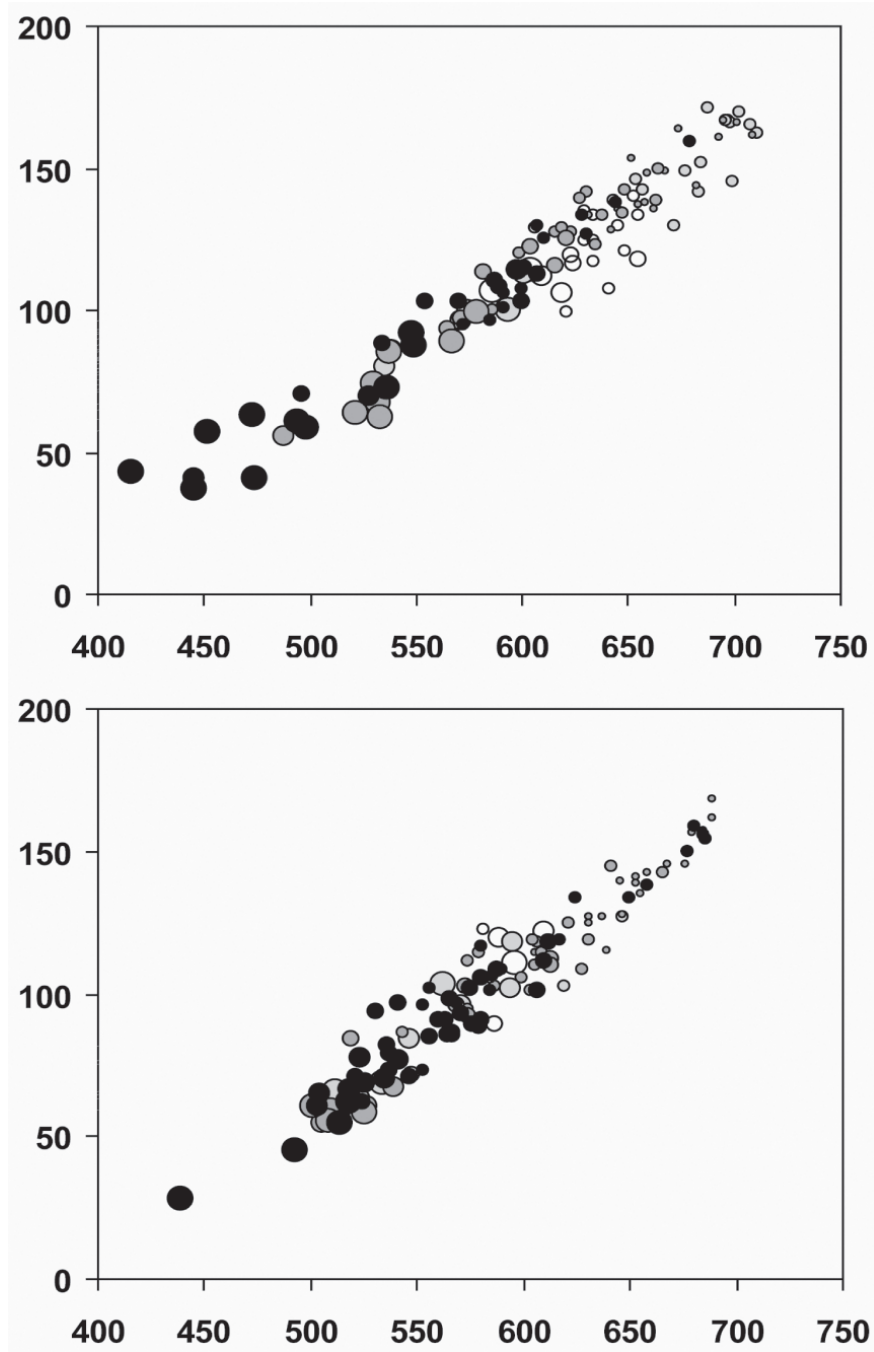

Fig. 10. Same as in Fig. 9, except for latent heat flux.

This result can be analyzed by examining the difference of temperature and water vapor between surface and lowest model layer. Figure 11 shows the difference between ground temperature and temperature at lowest model level versus the ground temperature for 1988 and 1989. The results indicate that the temperature difference tends to increase when ground temperature is increased. This phenomenon is attributed to the fact that ground warms up faster than the air, when solar radiation increases with decreasing low cloud cover. It is also seen that Fig. 12 shows the difference between surface saturated vapor mixing ratio and water vapor mixing ratio at the lowest model layer as a function of ground temperature. Similarly, the 
water vapor mixing ratio in the atmosphere is moistened slowly than the saturated vapor mixing ratio which is a function of ground temperature. Of course, there are variances in both Figs. 11 and 12, indicating that the air temperature and water vapor mixing ratio are affected by not only the sensible and latent heat fluxes, but also other factors, such as radiative horizon-
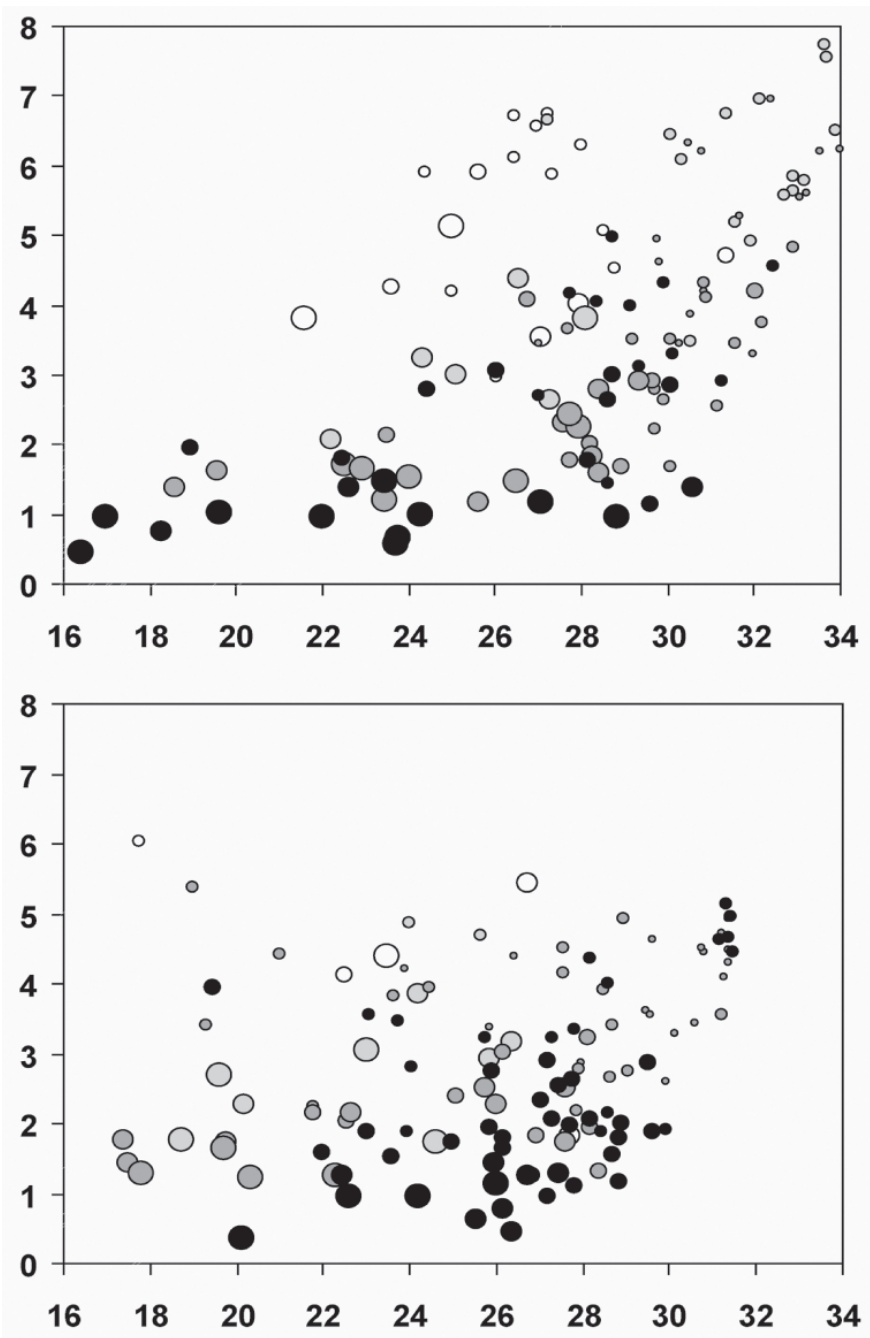

Fig. 11. Diagram of daily difference between mean ground temperature $\left({ }^{\circ} \mathrm{C}\right)$ and surface air temperature $\left({ }^{\circ} \mathrm{C}\right)$ against ground temperature $\left({ }^{\circ} \mathrm{C}\right)$ in May August of 1988 (upper) and 1989 (lower panel). Total cloud cover is indicated by four shading intervals from no shading to dark: 0 - 20\%, 20 - $50 \%, 50-75 \%$, and $75 \%-100 \%$. Ratio of low cloud cover and total cloud cover is depicted by five circles sizes at interval of 0.2 . 
tal advection and condensational heating. As a result, these surface-atmosphere difference of water vapor mixing ratio and temperature sometimes, especially the latter, are smaller when the total cloud cover or ratio of low cloud cover to total cloud cover is larger. These differences respectively determine the magnitudes of the sensible and latent heat fluxes, which therefore are indirectly influenced by the cloud vertical structure.
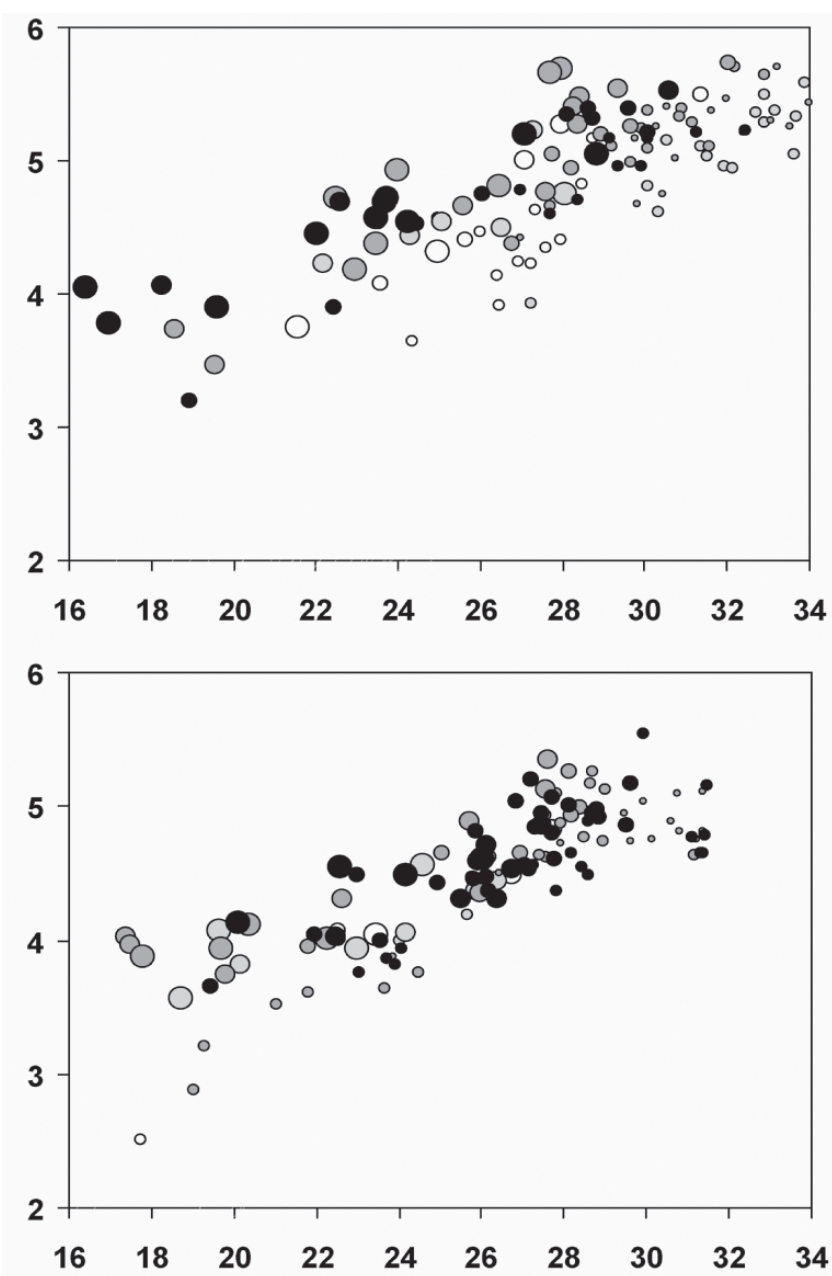

Fig. 12. Diagram of daily difference between ground saturated water vapor mixing ratio $\left(\mathrm{g} \mathrm{kg}^{-1}\right)$ and surface air temperature $\left(\mathrm{g} \mathrm{kg}^{-1}\right)$ against ground temperature $\left({ }^{\circ} \mathrm{C}\right)$ in May - August of 1988 (upper) and 1989 (lower panel). Total cloud cover is indicated by four shading intervals from no shading to dark: $0-20 \%, 20-50 \%, 50-75 \%$, and 75\% - 100\%. Ratio of low cloud cover and total cloud cover is depicted by five circles sizes at interval of 0.2 . 


\section{CONCLUSION AND DISCUSSION}

In this study, we use the State University of New York at Albany (SUNYA) regional climate model (RCM) to investigate the cloud vertical structure and its subsequent effects on surface energy components during the East Asian Summer Monsoon (EASM) in 1988 and 1989. Between these two years, significant differences are found in seasonal variations of shortwave (SW) cloud radiative forcing (CRF) at the top of atmosphere (TOA) from ERBE observational data.

The model result indicates that low and high clouds persist in the simulations, while middle cloud does not occur frequently. The low cloud effectively affects on surface energy components. It is shown that with the same total cloud cover, the more the low cloud, the more the decrease of surface downward solar radiative flux, because low cloud has larger cloud water content than high cloud. The low cloud also affects surface downward longwave radiative flux through its temperature. When temperature of low cloud is cold, the surface downward longwave radiative flux significantly decreases. Because effect of low cloud on the surface downward solar radiation effect is dominant, the surface net radiation decreases with the increase of low cloud. Therefore, ground temperature cools with the increase of low cloud, while the model results show that surface air temperature cools more slowly, thus leading to a decrease of the difference ground and surface air temperatures. For the same reason, the difference between surface saturated water vapor, which depends on ground temperature, and atmospheric water vapor also decreases. Consequently, the more the low cloud, the smaller the sensible and latent heat fluxes, which are primarily determined by the above-mentioned differences. Therefore, it is concluded that low cloud has significant effects on the surface energy balance, and indicating the importance of simulated cloud vertical structure.

In addition to the effects on surface energy components, cloud vertical structure also influences the TOA CRF. For both ERBE and SUNYA RCM, the high cloud cover increases the LW CRF, which acts to warm the earth-atmosphere, although the model under-simulates such effect. On the other hand, the simulated low cloud cover significantly increases the SW CRF, which has a cooling effect on the earth-atmosphere, in particular the intra-seasonal trend.

The above-mentioned effects of cloud structure are important to RCM validation. The model performance in regular variables, such as temperature and total cloud cover, is reasonably good. For example, over Yangtze-Huai River Valley (YHRV) the four-month mean temperature in 1988 and 1989 is, respectively, 24.90 and $23.35^{\circ} \mathrm{C}$, which are very close to observed 24.79 and $23.53^{\circ} \mathrm{C}$. Total cloud cover is, respectively, 58.81 and $69.35 \%$, which reasonably catches the observed interannual variability of 67.93 and $72.43 \%$ between 1988 and 1989. Despite these fair simulation of surface climate, model biases in other aspects, particularly the high cloud and its associated longwave (LW) CRF, are still large. Over YHRV the model simulated four-month mean LW CRF for the two years are 24.72 and $29.49 \mathrm{Wm}^{-2}$, which are almost smaller by a factor of 2 than the observed 46.76 and $51.70 \mathrm{Wm}^{-2}$. On the other hand, however, the RCM over-simulated the high cloud cover by about 8.64 and $19.21 \%$, respectively in 1988 and 1989. Therefore, it is not sufficient to evaluate the temperature and total cloud cover, the cloud vertical structure is a mandatory variable for model validation.

The under-simulation of LW CRF certainly is related to the cloud ice water in the RCM. 
Further researches on improving the cloud microphysics parameterization are warranted. Two approaches will be used to evaluate and undersand the simulated clouds ice water. One is to compare the simulated cloud ice water against observation, e.g., high resolution data from the Atmosphere Radiation Measurement (ARM) project. Secondly, we are currently inter-comparing EASM simulations using two RCMs developed at SUNYA and International Pacific Research Center, University of Hawaii (Wang et al. 2003), in which different cloud parameterization are used. The comparison of the two models, e.g. tendencies of cloud ice generation/removal, will provide more insights into understanding the characteristics of clouds and their interactions with climate state they embedded in.

\section{REFENECES}

Cheng, C. T., and W. C. Wang, 2005: Cloud parameterizations in SUNYA regional climate model for the East Asia summer monsoon simulation. Terr. Atmos. Ocean. Sci., 16, 959-987.

Ferretti, R., P. Tiziana, W. Zheng, G. Visconti, and P. Bonelli, 2000: Analyses of the precipitation pattern on the Alpine region using different cumulus convection parameterizations. J. Applied Meteorol., 39, 182-200.

Gong, W., and W. C. Wang, 2000: A regional model simulation of the 1991 severe precipitation event over the Yangtze-Huai River Valley, part II: Model bias. J. Climate, 13, 93108.

Iwasaki, T., and H. Kitagawa, 1998: Variation of summer water vapor transport related to a possible link of aerosol and cloud radiations to Asian summer monsoon and its implication in long-range numerical weather prediction. J. Meteorol. Soc. Japan, 76, 965-982.

Joseph, P. V., and S. Sijikumar, 2004: Intraseasonal variability of the Low-Level Jet Stream of the Asian summer monsoon. J. Climate, 17, 1449-1458.

Kiehl, J. T., J. J. Hack, G. B. Bonan, B. A. Boville, B. P. Briegleb, D. L. Williamson, and P. J. Rasch, 1996: Description of the NCAR Community Climate Model (CCM3), NCAR Tech. Note, NCAR/TN-420+STR, 152 pp.

Klein, S. A., and C. Jakob, 1999: Validation and sensitivities of frontal clouds simulated by the ECMWF model. Mon. Weather Rev., 127, 2514-2531.

Kuo, Y. H., R. Reed, and Y. Liu, 1996: The ERICA IOP 5 storm. Part III: Mesoscale cyclogenesis and precipitation parameterization. Mon. Weather Rev., 124, 1409-1434.

Liang, X. Z., and W. C. Wang, 1995: A GCM study of the climatic effect of 1979 - 1992 ozone trend. In: Wang, W. C., and I. S. A. Isaksen (Eds.), Atmospheric Ozone as a Climate Gas, NATO ASI Series, Springer-Verlag, 259-288.

Rajeevan, M., and J. Srinivasan, 2000: Net cloud radiative forcing at the top of the atmosphere in the Asian monsoon region. J. Climate, 13, 650-657.

Wang, W. C., W. Gong, and H. L. Wei, 2000: A regional model simulation of the 1991 severe precipitation event over the Yangtze-Huai River Valley. Part I: Precipitation and circulation statistics. J. Climate, 13, 74-92. 
Wang, W. C., W. Gong, W. S. Kau, C. T. Chen, H. H. Hsu, and C. H. Tu, 2004a: Characteristics of cloud radiation forcing over East China. J. Climate, 17, 845-853.

Wang, Y., O. L. Sen, and B. Wang, 2003: A highly resolved regional climate model (IPRCRegCM) and its simulation of the 1998 severe precipitation event over China. Part I: Model description and verification of simulation. J. Climate, 16, 1721-1738.

Wang, Y., L. R. Leung, J. L. McGregor, D. K. Lee, W. C. Wang, Y. Ding, and. F. Kimura, 2004b: Regional climate modeling: Progress, challenges, and prospects. J. Meteorol. Soc. Japan, 82, 1599-1628.

Yu, R., B. Wang, and T. Zhou, 2004: Climate effects of the deep continental stratus clouds generated by the Tibetan Plateau. J. Climate, 17, 2702-2713.

Gong, W., and W. C. Wang, 2007: SUNYA regional climate model simulations of East Asia summer monsoon: Effects of cloud vertical structure on the surface energy balance. Terr. Atmos. Ocean. Sci., 18, 493-514, doi: 10.3319/TAO.2007.18.3.493(EA). 